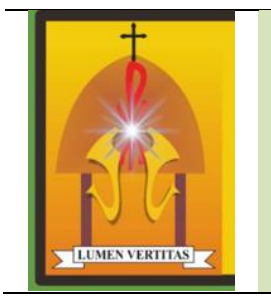

Original article
Contents available at: www.repository.unwira.ac.id

LUMEN VERITATIS

Jurnal Teologi dan Filsafat

https://journal.unwira.ac.id/index.php/LUMENVERITATIS

doi: 10.30822/lumenveritatis.v10i1.206

\title{
MODEL PENDIDIKAN MASA KINI
}

\author{
Kornelis Usboko \\ Program Studi Ilmu Filsafat, Fakultas Filsafat, Universitas Katolik Widya Mandira \\ Email: kornelis-usboko@yahoo.com
}

\begin{abstract}
"The goal of education according to Habermas is to humanize human being. There was a wise man from India ever said that an answer against one thousand problems was education. Nelson Mandela also said: education was the most powerful weapon that we could use to change the world. These all show us that education becomes a very urgent need of human life. Through education human being is processing to be more human and finding the solution against a number of problems of his/her life like poverty, ignorance and many other cases".
\end{abstract}

Keywords: model pendidikan, masa kini, memanusiakan manusia

\section{Pendahuluan}

Tujuan pendidikan menurut Habermars adalah memanusiakan manusia. Seorang bijak dari India pernah berujar: satu jawaban terhadap seribu persoalan adalah pendidikan. Nelson Mandela juga mengatakan bahwa pendidikan adalah senjata yang paling ampuh untuk menghancurkan berbagai belenggu. Hal ini menunjukkan bahwa pendidikan menjadi kebutuhan yang sangat urgen dalam kehidupan manusia. Melalui pendidikan, manusia berproses untuk menjadi lebih manusiawi, dan menemukan solusi terhadap sejumlah persoalan hidupnya seperti kemiskinan, kebodohan, rendahnya akhlak, moral dan etika, tata krama dalam besosialisasi dan berkomunikasi, serta sejumlah persoalan lainnya.

Pendidikan sebagai bagian dari pembangunan aklak dan moral telah lahir ribuan tahun silam. Titik mulanya adalah Yunani dalam rintisan Plato. Plato memulainya dengan mengajar para pemuda di kota Athena dalam tingkat akademi. Pada level ini para pemuda belajar logika, kemampuan menyampaikan pendapat, berorasi, berdebat, dan kemampuan bernalar. Plato meletakkan dasar rational dengan maksud agar setiap orang selalu 
menggunakan ratio dalam berbagi aspek kehidupan. Dengan demikian sesungguhnya semua orang mempunyai hak yang tidak dapat diganggu gugat atas pendidikan. ${ }^{1}$

Sayap pendidikan pada akhirnya berkembang ke semua negara termasuk Indonesia. Model pendidikan yang dibangun di Indonesia adalah pendidikan berjenjang mulai dari tingkat dasar hingga tingkat perguruan tinggi. Pendidikan kemudian dirangkum dalam suatu lembaga dengan tujuan agar mendapat pengawasan dari negara sehingga tidak melenceng dari tujuan awalnya yakni untuk mencerdaskan kehidupan bangsa (alinea IV UUD 45). Apabila bangsa menjadi cerdas maka bangsa ini akan keluar dari sejumlah persoalan yang melilit seperti kemiskinan, kebodohan pembagunan akhlak, dan juga sejumlah persoalan dalam kehidupan bernegara seperti layanan birokrasi, demokrasi (mampu mengaspirasikan pendapat dan memperjuangkan hak).

Pendidikan dalam prosesnya di Indonesia menuai sejumlah persoalan.

\footnotetext{
${ }^{1}$ Dokumen Konsili Vatikan II: Tentang Pendidikan
} Kristen, hal: 293
Bertolak dari pandangan Habermars di atas, pendidikan hadir untuk membangun manusia secara utuh yakni nalar/logika serta moral dan akhlak. Persoalan yang timbul dalam proses penyelenggaraan pendidikan adalah:

\section{Proses Pendidikan mengabaikan pembangunan mental}

Kecenderungan pendidikan masa kini adalah membangun manusia secara partial yakni hanya pada penguasaan IPTEK dan mengabaikan pembangunan moral etika. Fakta yang dapat diamati adalah pendidikan mencetak manusia yang brilian dalam penguasaan ilmu pengetahuan dan teknologi, tetapi keahlian tersebut digunakan untuk membunuh manusia itu sendiri melalui tindakan bom bunuh diri, teror bom, pembobolan ATM, bajak kapal laut, bajak pesawat, korupsi berdasi dan tersistem dan lain-lain. Situasi ini menghasilkan manusia Indonesia yang lemah integritas. Cirinya adalah bekerja dengan benar dan disiplin kalau sedang dalam pantauan, alias munafik. Menggunakan kekuasaan yang diperoleh 
melalui jabatan politik atau structural sebagai kesempatan untuk membangun system yang memungkinkan terjadinya KKN. Situasi ini kemudian memunculkan persoalan berantai dalam dunia pendidikan seperti politisasi pendidikan, pendidikan dijadikan sebagai lahan mencari popularitas, peluang bisnis. Persoalan tersebut di atas menyeret pendidikan kedalam lingkaran rantai hitam yang tunduk pada system yang sedang berkuasa, menyembah kekuatan ekonomi dan politik. Pada titik ini pendidikan kehilangan ciri independen dan fungsi kritik yang membangun demi mencapai cita-cita bangsa yang tertuang dalam alinea ke IV UUD 1945.

\section{Isu negeri dan swasta}

Mirisnya, isu ini muncul dari iklim yang dikondisikan oleh lembaga plat merah. Fakta ini bermula dari adanya perhatian terhadap kesejahteraan tenaga pendidik. Pemerintah lebih memprioritaskan tenaga pendidik yang mengabdi pada lembaga pendidikan berlabel negeri. Isu ini memunculkan kecenderungan sikap menganaktirikan lembaga pendidikan swasta teristimewa tenaga pendidiknya. Dampak ini makin meluas pada minat peserta didik yang lebih cenderung memilih sekolah negeri sebagai tempat menimba ilmu dibanding sekolah swasta, karena biaya sekolah negeri sangat murah, bahkan gratis. Isu ini makin lama makin menguat. Faktanya adalah rendahnya minat tenaga pendidik untuk mengabdi pada sekolah swasta, rendahnya minat peserta didik untuk mendaftar dan mengenyam pendidikan pada sekolah swasta. Pada dimensi ini kita menemukan bahwa tanpa disadari kita membangun sistem yang lebih pada mendewakan nama, label bukan pada proses. Masyarakat lebih merespon lembaga pendidikan berlabel negeri untuk mendapat perhatian ekstra dari negara bukan karena proses pendidikannya yang matang dan berkualitas (untuk NTT sekolah swasta masih unggul dan mengangkat nama daerah). Ini jelas menunjukkan bahwa masyarakat dan dunia pendidikan sedang memuja label bukan proses. Label bukan jaminan untuk menghasilkan anak didik yang lebih berkualitas, tetapi pada prosesnya. Proses pendidikan yang disiplin, yang benar, berkualitas akan 
menghasilkan manusia Indonesia yang berintegritas tinggi. $^{2}$

Tindakan mengabaikan proses dan memuja label melahirkan manusia instan. Cirinya adalah menginginkan hasil tanpa melalui proses perjuangan dan pengorbanan. Pendidikan dengan ciri ini menciptakan generasi yang cenderung bertindak brutal, tidak mampu mengontrol diri dan emosi, suka berteriak, memaksakan keinginan dan menjadi egois. Negara akan kehilangan generasi yang berjuang tanpa pamrih, rela berkorban, menghargai hasil karya dan keringat orang lain, mencintai rasa sakit yang timbul dari proses, bersikap optimis, pantang menyerah dan melihat kegagalan sebagai titik memulai proses baru dengan semangat juang yang lebih gigih.

Dampak lainnya adalah mematikan sekolah-sekolah swasta. Dikotomi swasta dan negeri secara tidak langsung membunuh sekolah swasta dan menumbuhkan pola pikir baru bahwa sector swasta bukanlah sector yang menjanjikan, lahan kelas dua, kurang bermasa depan dan sejumlah stigma buruk lainnya. Jika pola pikir ini tumbuh dan bermula dalam lingkungan pendidikan, bagaimana mungkin kita mampu menciptakan generasi enterpreuner, yang mampu berwiraswasta, menciptakan lapangan kerja, kalau dunia pendidikan sendiri memunculkan stigma bahwa lembaga swasta adalah lembaga kelas rendah. Campur tangan pemerintah yang berlebihan memperbesar bahaya etatisme. $^{3}$

Stigma swasta dan negeri bagai titik api. Percikannya kian hari kian melebar dan memunculkan titik-titik persoalan baru. Penyelenggaraan pendidikan sudah tidak profesional. Pendidikan keluar dari fungsi asalnya yakni sebagai jawaban atas persoalan-persoalan nyata manusia. Penyelenggaraan pendidikan justru memunculkan persoalan lain yang lebih besar. Persoalan yang bisa dilihat adalah pendidikan mencetak manusia berijasah tetapi tidak mampu berpikir dan bertindak lebih rational, menghasilkan manusia jenius tetapi bermental destruktif. Cirinya adalah memuja pikiran negative, tidak berjiwa membangun. Fakta yang bisa diamati adalah disiplin

\footnotetext{
${ }^{3}$ Nota Pastoral Tentang Pendidikan (KWI 2008), hal: 8
} 
yang rendah, korupsi atau yang lebih tragis adalah mengembangkan sikap teror melalui opini, bom bunuh diri, ancaman bom dan lain-lain. Persoalan lain dari dunia pendidikan masa kini adalah dunia pedidikan melahirkan masyarakat pendidikan yang tidak mampu memecahkan persoalan hidupnya sendiri seperti kemiskinan, pemenuhan lapangan kerja karena rendahnya kreatifitas. Dunia pendidikan dan lapangan kerja berlabel plat merah menjadi dewa, dianggap lebih bergengsi dibanding lapangan kerja dan dunia pendidikan swasta.

Persoalan ini justru menguras perhatian masyarakat pencinta pendidikan. Kita lebih sibuk mengurus label, bukan proses pendidikan, tujuan dan fungsi pendidikan, output dunia pendidikan. Persoalan label justru mengalihkan perhatian. Persoalan ini menunjukkan bahwa kita memiliki pandangan yang sempit terhadap hakekat dan eksistensi pendidikan. Persoalan ini membuat kita (Indonesia) tetap tertinggal dalam banyak hal, walau banyak hal positif dimiliki Indonesia. Bahwa sejatinya pendidikan sebagai sarana output manusia yang bermental dan berkarakter baik dan berwawasan luas sebenarnya bukan ditentukan oleh labelnya tetapi pada prosesnya. Di zaman Rousseau pendidikan dilaksanakan secara otoritatif dengan disiplin ketat dan nyaris mekanis sampai membuat peserta didik kurang bebas berpikir mandiri. Hal ini ditolak oleh Rousseau, Baginya pendidikan harus ditransformasikan sedemikian rupa untuk membawa perubahan. $^{4}$

Pada titik ini, semua elemen perlu berbenah untuk mengembalikan pendidikan pada fungsi asalinya yakni sebagai sarana pemecah persoalan manusia, dan sarana yang menjadikan manusia lebih manusiawi karena memiliki wawasan dan pengetahuan yang cukup serta karakter mental/spiritual, moral dan etika yang baik. Semua ini akan tercapai apabila pendidikan berproses secara benar. Proses yang benar akan mematangkan emosi mental dan ratio sehingga menciptakan output yang bermental dan memiliki ratio yang baik. Ratio dan mental yang tumbuh dari proses yang baik akan melahirkan

\footnotetext{
${ }^{4}$ F. Budi Hardiman., Filsafat Barat Modern, hal: 120
} 
manusia yang lebih respek dan dunia pendidikan akan melupakan berperilaku positif seperti disiplin, kerja hakekat dan nilai yang harus keras, bertanggung jawab, positive diperjuangkan. Dunia pendidikan akan thinking dan lain-lain.

Jika pendidikan berbicara tentang pembangunan manusia untuk menjadi lebih manusiawi dan menciptakan output yang mampu menjawabi persoalan hidupnya melalui tindakan berpikir dan sikap (attitude) maka kita menemukan bahwa pendidikan mengemban fungsi ganda. Pendidikan tidak hanya mendidik ratio tetapi juga membangun karakter: spiritual, moral dan etika. Bagaimana mungkin pendidikan mampu berdiri kokoh dan berteriak dengan lantang untuk hal-hal tersebut jika dunia pendidikan sendiri tidak mampu memecahkan persoalan dalam dirinya. Kelihatannya dunia pendidikan lebih focus pada persoalan sepele seperti label swasta dan negeri, mengabaikan proses, cenderung terlibat dan dikendalikan oleh iklim demokrasi electoral, cenderung menjadikan dunia pendidikan sebagai lahan bisnis, kasta kelas elit dan kelas pinggiran.

Apabila dunia pendidikan semakin tenggelam dan sibuk dengan persoalanpersoalan sepele tersebut di atas maka kehilangan wibawa dan dikuasai oleh pelaku bisnis dan politik electoral. Jika demikian maka pendidikan kehilangan martabat sebagai proses mendidik dan mencerahkan mental dan ratio generasi bangsa. Dunia pendidikan sebagai tempat membangun pola pikir yang baik, mental yang baik demi kemajuan bangsa akan lambat laun menjadi hilang. Jika ini makin dibiarkan, kita akan menemukan generasi baru yang bersifat destruktif, dehumanis. Ciri perilakunya adalah lebih bangga terhadap hal-hal yang rendah dan negative seperti pandai korup, hebat berkelahi, pintar berkelit, pandai berbohong dan lain-lain. Jika kita hidup dalam situasi, pola pikir dan suasana demikian maka lambat laun kita akan tidak mampu membedakan mana yang prinsip, mana yang benar, mana yang tidak boleh. Kita akan mencapuradukan kebohongan dan kejujuran, kesalahan dalam kebenaran demi keuntungan pribadi, pemenuhan ego, langgengnya jabatan politik, mencari rasa aman dan lain-lain. 


\section{Adanya ketidakadilan distributif}

Ketidakadilan yang dimaksud di sini adalah tidak adanya bentuk perhatian yang sama dan seimbang antara sekolah di kota dan sekolah di desa. Perhatian dimaksud adalah adanya penyaluran fasilitas pendidikan dan tenaga pendidik yang merata dan seimbang antara sekolah-sekolah di kota dan desa. Sekolah-sekolah dikota mendapat fasilitas dan tenaga pendidik yang cukup dibanding sekolah-sekolah di desa. Hal ini menyebabkan peserta didik dari kalangan ekonomi mampu lebih memilih mengenyam pendidikan di kota daripada di desa. Sejumlah persolan yang muncul dari situasi ini adalah mobilisasi penduduk generasi muda dari desa ke kota semakin tinggi. Fakta ini menyebabkan adanya desa menjadi sepi, perputaran uang di kota menjadi lebih cepat dan lancar karena uang yang ada di desa dibawa dan dibelanjakan di kota, pertumbuhan fasilitas di kota menjadi lebih cepat karena daya beli masyarakat semakin tingi sementara roda perekonomian di desa menjadi semakin layu. Pada titik ini tanpa disadari dunia pendidikan sedang membangun sistem yang secara tidak langsung membunuh desa, menghambat pembangunan yang dicanangkan oleh pemerintah sekarang yakni membangun dari desa, memberdayakan desa, membuat desa bergeliat dan menjadi lebih hidup.

Persoalan lainnya adalah kwalitas output berbeda walaupun memliliki tingkat ijasah yang sama. Hal ini disebabkan karena fasilitas pendidikan dan tenaga pendidik yang berbeda dalam dunia pendidikan. Kualitas fasilitas dan tenaga pendidik menyebabkan proses transfer ilmu pengethuan, teknologi dan pembangunan aklak menjadi semakin mudah. Sekolah-sekolah tertentu mendapat label sekolah elit dengan fasilitas dan tenaga pendidik yang mewah sementara ada sekolah kelas masyarakat pinggiran, kelompok ekonomi lemah dengan fasilitas serba terbatas dan kekurangan. Hal ini menyebabkan adanya tingkat perbedaan penguasaan ketrampilan, pengetahuan dan wawasan yang tidak merata di antara para out put. Pada titik ini kita menemukan adanya tindak diskriminatif dalam dunia pendidikan, pembagian kasta karena adanya kasta elit dan kelas rendah.

Pemerintah sebagai sebuah lembaga yang memiliki fungsi kontrol 
mengabaikan tanggung jawabnya. Hal ini disebabkan oleh karena takut dihukum dalam kotak suara, takut kehilangan simpati, tidak mampu bertindak tegas untuk menegakkan wibawa dan fungsi otentik dunia pendidikan karena memiliki kepentingan politik dalam dunia demokrasi elektoral. Aparatur pemerintah yang bertanggungjawab dalam mengatur dan mengontrol dunia pendidikan sering tidak bersuara dan menjadi inkonsisten dalam membangun nalarnya tentang pendidikan. Tindakan inkonsisten yang dimaksud adalah adanya konsep dualisme terhadap pendidikan. Ketika berada di antara kelompok elit aparatur penanggung jawab berlaku sebagai kelompok elit, ikut mendukung prilaku elit dan menjadi warga elit. Aparatur penanggungjawab tidak berani bertindak tegas untuk menarik tenaga pendidik, sarana pendidikan untuk didistribusikan kepada kelompok pinggiran. Demikian pula, ketika berada dalam kelompok pinggiran aparatur penanggungjawab tidak berani menutup sekolah yang tidak layak karena tidak memenuhi syarat dari segi tenaga pendidik dan fasilitas pendidikan. Sarana belajar yang tidak layak dan kualitas tenaga pendidik yang minim dibiarkan dan proses pendidikan yang berjalan dalam situasi serba kekurangan dibiarkan terjadi. Hasilnya dapat dipastikan bahwa sedikit lebih rendah dibanding peserta didik yang beruntung dan mengenyam pendidikan di sekolah elit.

Pemerintah sebagai penanggung jawab mestinya membantu mengangkat sekolah-sekolah swasta dan negeri kelas pinggiran untuk berdiri sama tinggi dan sejajar dengan sekolah-sekolah elit. Hal ini bukanlah sesuatu yang mustahil karena negara-negara lain telah menerapkannya. Misalnya di Kanada, Australia. Pemerintah bertanggung jawab penuh dalam menyediakan fasilitas dan tenaga pendidik sehingga tidak terciptanya sekolah elit dan sekolah kelas bawah.

Jika demikian maka kwalitas pendidikan berjalan kian merata, keadilan distributif di bidang pendidikan makin terasa, tidak tercipta golongan atau kelas dalam dunia pendidikan. Dengan demikian setiap subyek akan memiliki konsep yang sama, berpikir dalam taraf kwalitas yang sama mengenai output, dan kembali kepada hakekat dan eksistensi pendidikan dalam pandangan Habermars 
yakni menjadikan manusia lebih manusia. Manusia yang dimaksud adalah subyek yang terdiri dari jiwa dan raga ratio dan mental. Dalam konteksnya tentang Indonesia, pendidikan menjadi sarana mencerdaskan kehidupan bangsa.

Pemerataan konsep dimaksud adalah bahwa di daerah manapun, di lembaga pendidikan manapun, output yang dihasilkan akan memiliki jiwa dan karakter tutwuri handayani, ing madyomangun karsa, dan ing ngarso sung tulodo. Output dunia pendidikan ketika menjadi pemimpin dalam garda terdepan, mampu memberi teladan dalam dimensi berpikir, membangun opini publik, dan mampu membangun semamgat dan dukungan yang positif.

Nilai-nilai luhur bangsa dalam dunia pendidikan dalam konteks budaya Indoesia ini justru makin pudar di tengah demokrasi elektoral. Bias demokrasi elektoral telah menyusup ke dalam dunia pendidikan sehingga iklim saling menyemangati, memberi teladan makin terabaikan. Stakeholder di bidang pendidikan diangkat berdasarkan kepentingan atasan, bukan pada prinsip the right man on the right place. Budaya lawan dan kawan mulai dibangun secara sistematis dalam lembaga pendidikan. Kita bisa menemukan adanya berbagai kubu dalam satu lembaga pendidikan, blok A, blok B dan blok netral. Situasi ini cenderung menciptakan iklim yang kurang kondusif, dan para pelaku pendidikan cenderung bekerja berdasarkan kepentingan politik, bukan untuk tujuan pendidikan.

\section{Daftar referensi}

Atmadi, A. dan Setiyaningsih, Y. (Editor). Transformasi Pendidikan Memasuki Milenium Ketiga. Yogyakarta: Kanisius, 2000

Awam Katolik di Sekolah: Saksi-saksi Iman. Jakarta: Komisi Pendidikan KWI, 2008

Dokumen Konsili Vatikan II: Departemen Dokumentasi dan Penerangan KWI, Jakarta: 1998

F. Budi Hardiman, Filsafat Modern, Jakarta: Penerbit PT Gramedia Pustaka Utama, 2004

Kitab Hukum Kanonik tentang Pendidikan Katolik. Jakarta: Komisi Pendidikan KWI, 2008

Mochtar Buchori, Evolusi Pendidikan di Indonesia, Yogyakarta: Insist Press, 2007

Nota Pastoral Tentang Pendidikan, KWI: 2008 
LUMEN VERITATIS: Jurnal Filsafat dan Teologi, Volume. 12, Nomor 1, Oktober 2019 pSSN 1978-3469; eISSN 2657-1927 